\title{
Renin-angiotensin system inhibition is associated with reduced risk of left atrial appendage thrombosis formation in patients with atrial fibrillation
}

\author{
Ya Suo $^{1 *}$, Yue Zhang ${ }^{1 *}$, Yuanyuan Wang ${ }^{1}$, Meng Yuan ${ }^{1}$, Sayuri Kariyawasam ${ }^{1}$, \\ Gary $\mathrm{Tse}^{2,3}$, Tong $\mathrm{Liu}^{1}$, Huaying $\mathrm{Fu}^{1}$, Guangping $\mathrm{Li}^{1}$ \\ ${ }^{1}$ Tianjin Key Laboratory of Ionic-Molecular Function of Cardiovascular Disease, Tianjin Institute \\ of Cardiology, Department of Cardiology, Second Hospital of Tianjin Medical University, Tianjin, \\ People's Republic of China \\ ${ }^{2}$ Department of Medicine and Therapeutics, Chinese University of Hong Kong, Hong Kong, \\ SAR, People's Republic of China \\ ${ }^{3} \mathrm{Li}$ Ka Shing Institute of Health Sciences, Chinese University of Hong Kong, \\ Hong Kong, SAR, People's Republic of China
}

\begin{abstract}
Background: Inhibition of the renin-angiotensin axis can reduce the likelihood of atrial fibrillation $(A F)$. However, the effects of angiotensin-converting-enzyme inhibitors (ACEIs) or angiotensin II receptor blockers (ARBs) on thrombogenicity in AF remain incompletely elucidated. Thisretrospective case-control study was conducted to evaluate whether the use of ACEI or ARB could reduce the incidence of left atrial appendage thrombus (LAAT) and spontaneous echocardiographic contrast (SEC) in patients with AF.

Methods: A total of 199 AF patients who received both transesophageal echocardiogram (TEE) and transthoracic echocardiogram (TTE) successively on the same day from 2012 to 2016 were enrolled. Left atrial dimension, maximal left atrial volume (LAVmax), left ventricular end-diastolic dimension, left ventricular ejection fraction, and the ratio of the early transmitral flow velocity and the early mitral annular velocity (E/e') were determined. Longitudinal LA strain was evaluated using two-dimensional speckle tracking imaging at each LA segment. Peak systolic strain was calculated by averaging total segments. LAAT, LAA emptying flow velocity (LAAeV) and SEC were evaluated by TEE. Risk factors for LAAT and usage of ACEIs or ARBs were recorded.

Results: The incidence of LAAT was 27.6\%. Among the patients with renin-angiotensin system (RAS) inhibitors, $20.5 \%$ were demonstrated to have LAAT, compared with $33.3 \%$ in the nonuser group $(p=0.044)$. LA peak systolic strain and LAAeV were significantly increased in patients with RAS inhibitors compared to the nonuser group $(p=0.002, p=0.047$, respectively). Patients with LAAT had higher $\mathrm{CHA}_{2} D S_{2}$-VASc scores and evident SEC compared with those without LAAT ( $p=0.000, p=0.000$, respectively). Usage of ACEIs/ARBs and antiplatelet drugs were frequent in patients with LAAT than in those without LAAT $(p=0.044$, $p=0.000$, respectively). Even after controlling for LAAT-related risk factors (age, body mass index, AF type, hypertension, diabetes mellitus, prior stroke or transient ischemic attack, drinking history and usage of antiplatelet drugs and LAVmax), use of RAS inhibitors remained significantly associated with a lower risk of $L A A T(O R=0.222 ; 95 \%$ CI 0.084-0.585, $p=0.002)$.

Conclusions: This study shows that RAS inhibitors may be effective in reducing the risk of LAAT in patients with AF through atrial reverse remodeling. (Cardiol J 2018; 25, 5: 611-620)
\end{abstract}

Key words: atrial fibrillation, thrombus, renin-angiotensin, atrial strain

Address for correspondence: Guangping Li, MD, PhD; Huaying Fu, MD, PhD, Tianjin institute of Cardiology,

The $2^{\text {nd }}$ Hospital of Tianjin Medical University, Tianjin, China, 300211, People's Republic of China,

e-mail: tjcardiol@126.com; Huayingfu@126.com

Received: 13.03.2017 Accepted: 09.09.2017

*Both authors have contributed equally to this work. 


\section{Introduction}

Non-valvular atrial fibrillation (AF) is the most common sustained cardiac arrhythmia, increasing the risk of cardio-embolic stroke [1]. Left atrial appendage (LAA) is a primary source of thromboembolism in stroke patients with AF [2]. Transesophageal echocardiography (TEE) can be used to identify left atrial appendage thrombus (LAAT) and spontaneous echo contrast (SEC). The latter is a known precursor of LAAT and systemic thromboembolism [3].

Many clinical studies have demonstrated that left atrial (LA) mechanical remodeling could result in thrombus formation in the LAA [4, 5]. $\mathrm{AF}$ is associated with activation of the renin-angiotensin system (RAS) in the atria locally. This can lead to both structural and electrophysiological remodeling, leading to higher susceptibility to arrhythmogenesis [6]. LA peak systolic strain measured by two-dimensional (2D) speckle tracking, decreased with progressive LA enlargement, is inversely related to atrial fibrosis and stiffness. LA peak systolic strain shows the potential as a marker of LA mechanical and structural remodeling [7].

More recent studies have implicated pro-thrombotic effects of RAS activation, and inhibition of this pathway can reduce the propensity to developing $\mathrm{AF}$ through reverse remodeling [8, 9]. However, whether angiotensin converting enzyme inhibitors (ACEIs) or angiotensin II receptor blockers (ARBs) can prevent LAAT has not been studied in a clinical context. In this study, it was hypothesized that inhibition of RAS can reduce the incidence of LAAT in patients with $\mathrm{AF}$ through reverse remodeling.

\section{Methods}

\section{Patient populations}

This is a retrospective study, including all consecutive adult patients with AF who underwent both transthoracic echocardiography (TTE) and TEE to determine the presence or absence of LAAT from January 1, 2012 to December 31, 2016 admitted to the Second Hospital of Tianjin Medical University. Demographic details, use of RAS inhibitors and risk factors for LAAT on admission were recorded and entered into pre-designed spreadsheets. To minimize subjective judgment and selection bias, investigators were blinded to outcomes. Patients who have never used RAS inhibitors or who have used them for less than 3 months were assigned to the nonuser group. Patients who had used either ACEI or ARB for at least 3 months were classified into the user group. The dosage of ACEIs or ARBs was adjusted according to blood pressure and clinical parameters. Patients who were treated with anticoagulation therapy prior to the visit were excluded. Patients with previous history of LAAT were excluded. Other exclusion criteria were significant valvular disease, previous valve replacement or reconstruction, intracardiac shunting, left ventricular (LV) systolic dysfunction defined as LV ejection fraction (LVEF) $\leq 40 \%$, acute myocardial infarction, hyperthyroidism, primary pulmonary hypertension and respiratory disease. Patients who showed inadequate quality of echocardiographic images were also excluded. The outcome of the present study was the occurrence of LAAT (LAA thrombus and/or sludge).

\section{Echocardiography}

Echocardiographic examination was performed using a commercial ultrasound system (IE33, Philips Healthcare, Inc.). TEE examination was conducted with a $3 \mathrm{D}$ matrix array probe (X7-2t, carrier frequency $2-7 \mathrm{MHz}$ ), whereas TTE examination was performed using a $1-5 \mathrm{MHz}$ phased S5-1 probe. All images were digitally stored and analyzed using off-line post processing with QLAB Software packages. The following parameters were evaluated in standard views with standard techniques [10]: left atrial dimension (LAD), maximal left atrial volume (LAVmax), left ventricular enddiastolic dimension (LVDd), LVEF, and the ratio of the early transmitral flow velocity and the early mitral annular velocity (E/e'). Tissue Doppler velocities were measured at the septal annuli using spectral Doppler tissue imaging.

An echocardiographer, who was blinded to the TTE and clinical data, reviewed all TEE images to determine the presence or absence of LAAT [LAAT $(+)$ and LAAT(-)], SEC and depressed left atrial appendage emptying velocity (LAAeV) $(<40 \mathrm{~cm} / \mathrm{s})$ by pulsed wave Doppler. LAAT was defined as a circumscribed and uniformly echo dense intracavitary mass distinct from the underlying LA or LAA endocardium and the pectinate muscles, and present in more than one imaging plane [11]. SEC was defined as dynamic "smoke-like" echoes with the characteristic swirling motion with optimal gain setting during the entire cardiac cycle [12]. The definition of optimal gain is that images should provide an adequate endocardial definition to assess morphology and motion accurately and quantify subtle echocardiographic changes associated with SEC. SEC was graded based on Fatkin's classification $(1$ to $4+)$ [13]. When dense SEC (grade 3+ 


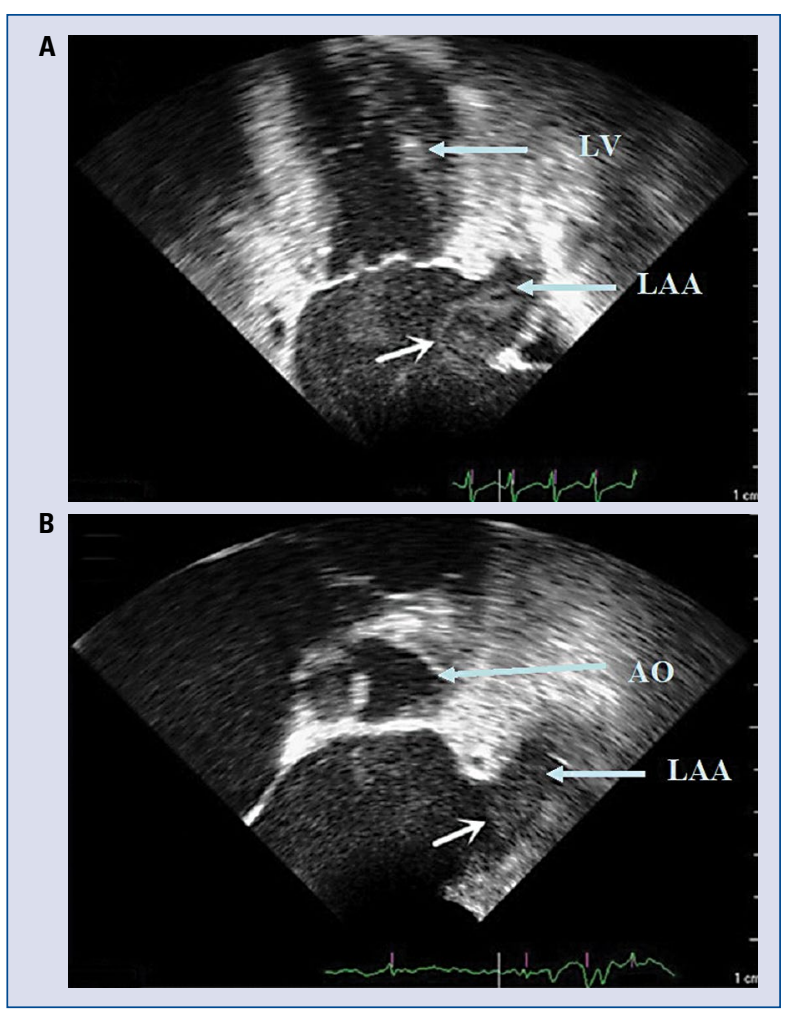

Figure 1. Representative examples of left atrial appendage thrombus (LAAT) and spontaneous echocardiographic contrast in patients with atrial fibrillation; $\mathbf{A}$. Left atrial appendage (LAA) sludge; B. LAAT; AO - aorta; LV - left ventricle.

or $4+$ ) was present and organized into a dynamic and gelatinous, but not solid or well-formed, echodensity present throughout the cardiac cycle, sludge was reported [14]. LAA sludge was categorized as LAAT [15]. In the present study, it was classified LAA sludge as LAAT (Fig. 1).

Left atrial strain was estimated as the average of longitudinal strain data from the apical 4-chamber, 2-chamber and apical long axis views. The LA myocardium was divided into 5 regions of equal area. Five segments from the apical 4- and 2 -chamber views were analyzed, whereas only 3 segments in the apical long axis view were analyzed because the remaining 2 segments in this view are parts of the aortic valve and ascending aorta. A total of 13 LA segments were analyzed. The LA peak systolic strain during ventricular systole was calculated by taking the mean for all 13 segments. In patients with $\mathrm{AF}$, echocardiographic parameters such as LA strain were calculated as the mean values from 5 cardiac cycles. Parameters weree carefully measured only in those cycles in which the preceding and measured cardiac cycles were nearly equivalent.

The study protocol was approved by the Second Hospital of Tianjin Medical University Institutional Review Board.

\section{Statistical analysis}

Results were presented as means \pm standard deviation (SD) for continuous variables and as percentages of the total number of patients for categorical variables. All statistical analyses were performed using SPSS (version 23.0, SPSS, Chicago, IL, USA). Chi-square and the Fisher exact test were used for nominal variables. Student t-test was used for comparison of continuous variables. Levene's test was used in order to check the homogeneity of variance. Equivalent non-parametric tests were used when Kolmogorov-Smirnov was in favor of non-normal distribution. Results with $\mathrm{p}<0.05$ were regarded as statistically significant. Univariate analysis was performed using the $\chi^{2}$ test. Variables that were significant on univariate logistic regression analysis $(p<0.05)$ were entered into the multivariate analysis. Logistic regression analysis (using the enter method) was performed to identify independent predictors for LAAT. Risk was expressed as oddratios $(\mathrm{OR})$ with $95 \%$ confidence intervals $(\mathrm{CI})$. The Hosmer-Lemeshow summary statistic was used to assess the goodness-of-fit of the models.

\section{Results}

Initially, 429 patients with $\mathrm{AF}$ who underwent TEE between 2012 and 2016 were identified. After assessing them against the exclusion criteria, a total of 199 patients were included in the final analysis. The average age of the whole cohort was $61.36 \pm$ \pm 9.49 years. $58.8 \%$ of the patients were male. Patients were categorized into two groups based on whether or not they had used ACEIs/ARBs. Among these patients, 88 (44.2\%) were using RAS inhibitors, either ACEIs (40.9\%) or ARBs (59.1\%). Clinical characteristics and echocardiographic parameters were compared between the ACEIs/ /ARBs user and non-user groups (Table 1). ACEIs/ /ARBs users had a higher prevalence of hypertension than non-users, but other demographic and clinical characteristics were comparable between these groups. LAAT occurred in $27.6 \%$ of the entire cohort (55/199 subjects), including $20.5 \%$ users of ACEIs/ARBs compared to $33.3 \%$ in non-users. Users of ACEIs/ARBs had lower LAVmax, higher LA peak systolic strain and higher LAAeV compared to 
Table 1. Clinical and echocardiography parameters between ACEls/ARBs users and nonusers group.

\begin{tabular}{|c|c|c|c|}
\hline Variables & ACEls/ARBs user $(n=88)$ & ACEls/ARBs nonuser $(n=111)$ & $\mathbf{P}$ \\
\hline Age [years] & $62.772 \pm 8.184$ & $60.243 \pm 10.307$ & 0.055 \\
\hline Age $\geq 65$ years & $38(43.1 \%)$ & $43(38.7 \%)$ & 0.526 \\
\hline Male gender & $48(54.5 \%)$ & $69(62.2 \%)$ & 0.278 \\
\hline BMI $\left[\mathrm{kg} / \mathrm{m}^{2}\right]$ & $26.295 \pm 3.899$ & $25.531 \pm 3.087$ & 0.135 \\
\hline AF type: & $88(44.2 \%)$ & $111(55.8 \%)$ & 0.457 \\
\hline Paroxysmal AF & $68(77.3 \%)$ & $86(77.5 \%)$ & 0.973 \\
\hline Persistent AF & $18(20.5 \%)$ & $19(17.1 \%)$ & 0.548 \\
\hline Long standing persistent AF & $2(2.3 \%)$ & $6(5.4 \%)$ & 0.306 \\
\hline Old myocardial infarction & $5(5.7 \%)$ & $3(2.7 \%)$ & 0.470 \\
\hline Vascular disease & $4(4.5 \%)$ & $6(5.4 \%)$ & 1.000 \\
\hline Coronary heart disease & $66(75 \%)$ & $69(62.2 \%)$ & 0.054 \\
\hline Hyperlipidemia & $59(67 \%)$ & $70(63.1 \%)$ & 0.559 \\
\hline Hypertension & $77(87.5 \%)$ & $54(48.6 \%)$ & 0.000 \\
\hline Diabetes mellitus & $23(26.1 \%)$ & $21(18.9 \%)$ & 0.223 \\
\hline Congestive heart failure & $6(6.8 \%)$ & $4(3.6 \%)$ & 0.342 \\
\hline Prior stroke or TIA & $10(11.4 \%)$ & $11(9.9 \%)$ & 0.740 \\
\hline $\mathrm{CHA}_{2} \mathrm{DS}_{2}$-VASc score & $2.465 \pm 1.372$ & $1.828 \pm 1.476$ & 0.002 \\
\hline Smoking history & $35(39.8 \%)$ & $40(36 \%)$ & 0.589 \\
\hline Drinking history & $21(23.9 \%)$ & $19(17.1 \%)$ & 0.238 \\
\hline Antiplatelet drugs & $50(56.8 \%)$ & $50(45 \%)$ & 0.099 \\
\hline Statins & $43(48.9 \%)$ & $52(46.8 \%)$ & 0.777 \\
\hline BUN [mmol/L] & $5.805 \pm 1.552$ & $6.009 \pm 1.777$ & 0.395 \\
\hline Serum creatinine $[\mu \mathrm{mol} / \mathrm{L}]$ & $78.430 \pm 25.829$ & $74.205 \pm 25.086$ & 0.246 \\
\hline $\mathrm{LAD}[\mathrm{mm}]$ & $39.406 \pm 3.883$ & $40.681 \pm 6.191$ & 0.078 \\
\hline LAVmax $[\mathrm{mL}]$ & $50.446 \pm 14.604$ & $56.201 \pm 23.345$ & 0.035 \\
\hline LVDd [mm] & $49.355 \pm 6.368$ & $47.939 \pm 4.023$ & 0.071 \\
\hline LVEF [\%] & $57.556 \pm 6.438$ & $59.165 \pm 6.039$ & 0.074 \\
\hline E/e' ratio & $12.168 \pm 4.452$ & $13.857 \pm 5.543$ & 0.018 \\
\hline LAAeV $[\mathrm{cm} / \mathrm{s}]$ & $47.415 \pm 19.703$ & $41.486 \pm 21.613$ & 0.047 \\
\hline LA peak systolic strain [\%] & $33.756 \pm 13.148$ & $27.859 \pm 12.688$ & 0.002 \\
\hline SEC & $31(35.2 \%)$ & $55(49.5 \%)$ & 0.043 \\
\hline LAAT & $18(20.5 \%)$ & $37(33.3 \%)$ & 0.044 \\
\hline
\end{tabular}

Data are shown as number (percentage) or mean \pm standard deviation. ACEI/ARB - angiotensin converting enzyme inhibitors/angiotensin II receptor blockers; AF — atrial fibrillation; BMI — body mass index; BUN — blood urea nitrogen; E/e' ratio - the ratio of the early transmitral flow velocity and the early mitral annular velocity; LA — left atrium; LAAeV — LAA emptying flow velocity; LAAT — left atrial appendage thrombus; LAD - left atrial dimension; LAVmax - maximal left atrial volume; LVDd — left ventricular end-diastolic dimension; LVEF - left ventricular ejection fraction; SEC — spontaneous echocardiographic contrast; TIA — transient ischemic attack

non-users. No significant differences in LAD, LVDd and LVEF were observed between these groups.

There were $43.2 \%(n=86)$ patients showed SEC. According to the type of findings on TEE, the patients were divided into two groups: patients with LAAT (LAA thrombus and/or sludge) and patients without LAAT. Clinical characteristics and echocardiographic parameters of the patients with or without LAAT are shown in Table 2. Patients without LAAT $(60.3 \pm 9.8$ years $)$ were younger than patients with LAAT $(63.9 \pm 7.9$ years $)(\mathrm{p}<$ $<0.05)$. Body mass index (BMI) and $\mathrm{CHA}_{2} \mathrm{DS}_{2}$ VASc scores were significantly higher in patients with LAAT compared to those without LAAT. Compared to patients without LAAT, patients with LAAT had a higher prevalence of persistent AF, long standing persistent AF, hypertension, diabetes mellitus, prior stroke or transient ischemic attack (TIA). 
Table 2. Clinical and echocardiography parameters of patients with or without LAAT.

\begin{tabular}{|c|c|c|c|}
\hline Variables & LAAT $(+)(n=55)$ & LAAT (-) (n = 144) & $\mathbf{P}$ \\
\hline Age [years] & $63.927 \pm 7.927$ & $60.381 \pm 9.871$ & 0.018 \\
\hline Age $\geq 65$ years & $31(56.4 \%)$ & $50(34.7 \%)$ & 0.005 \\
\hline Male gender & $36(65.5 \%)$ & $81(56.3 \%)$ & 0.238 \\
\hline BMI $\left[\mathrm{kg} / \mathrm{m}^{2}\right]$ & $26.661 \pm 3.464$ & $25.566 \pm 3.451$ & 0.047 \\
\hline AF type: & $55(27.6 \%)$ & $144(72.4 \%)$ & 0.000 \\
\hline Paroxysmal AF & $28(50.9 \%)$ & $126(87.5 \%)$ & 0.000 \\
\hline Persistent AF & $20(36.4 \%)$ & $17(11.8 \%)$ & 0.000 \\
\hline Long standing persistent AF & $7(12.7 \%)$ & $1(0.7 \%)$ & 0.001 \\
\hline Old myocardial infarction & $2(3.6 \%)$ & $6(4.2 \%)$ & 1.000 \\
\hline Vascular disease & $4(7.3 \%)$ & $6(4.2 \%)$ & 0.468 \\
\hline Coronary heart disease & $41(74.5 \%)$ & $94(65.3 \%)$ & 0.211 \\
\hline Hyperlipidemia & $39(70.9 \%)$ & $90(62.5 \%)$ & 0.267 \\
\hline Hypertension & $45(81.8 \%)$ & $86(59.7 \%)$ & 0.003 \\
\hline Diabetes mellitus & $18(32.7 \%)$ & $26(18.1 \%)$ & 0.026 \\
\hline Congestive heart failure & $5(9.1 \%)$ & $5(3.5 \%)$ & 0.143 \\
\hline Prior stroke or TIA & $19(34.5 \%)$ & $2(1.4 \%)$ & 0.000 \\
\hline $\mathrm{CHA}_{2} \mathrm{DS}_{2}$-VASc score & $2.963 \pm 1.643$ & $1.784 \pm 1.246$ & 0.000 \\
\hline Smoking history & $21(38.2 \%)$ & $54(37.5 \%)$ & 0.929 \\
\hline Drinking history & $16(29.1 \%)$ & $24(16.7 \%)$ & 0.050 \\
\hline ACEI/ARB: & $18(32.7 \%)$ & $70(48.6 \%)$ & 0.044 \\
\hline ACEI & $9(16.4 \%)$ & $27(18.8 \%)$ & 0.696 \\
\hline ARB & $9(16.4 \%)$ & $43(29.9 \%)$ & 0.053 \\
\hline Antiplatelet drugs & $15(27.3 \%)$ & $85(59.0 \%)$ & 0.000 \\
\hline Statins & $26(47.3 \%)$ & $69(47.9 \%)$ & 0.935 \\
\hline BUN $[\mathrm{mmol} / \mathrm{L}]$ & $5.680 \pm 1.783$ & $6.010 \pm 1.636$ & 0.215 \\
\hline Serum creatinine $[\mu \mathrm{mol} / L]$ & $75.827 \pm 24.465$ & $76.168 \pm 25.885$ & 0.933 \\
\hline SEC & $55(100 \%)$ & $31(21.5 \%)$ & 0.000 \\
\hline LAD [mm] & $44.099 \pm 5.015$ & $38.597 \pm 4.614$ & 0.000 \\
\hline LAVmax $[\mathrm{mL}]$ & $66.838 \pm 21.684$ & $48.622 \pm 17.043$ & 0.000 \\
\hline LAVmax $\geq 50 \mathrm{~mL}$ & $45(81.8 \%)$ & $66(45.8 \%)$ & 0.000 \\
\hline LVDd $[\mathrm{mm}]$ & $48.698 \pm 5.433$ & $48.514 \pm 5.162$ & 0.825 \\
\hline LVEF [\%] & $57.729 \pm 4.996$ & $58.730 \pm 6.668$ & 0.254 \\
\hline $\mathrm{E}: \mathrm{e}^{\prime}$ ratio & $18.087 \pm 3.968$ & $11.209 \pm 4.190$ & 0.000 \\
\hline LAAeV $[\mathrm{cm} / \mathrm{s}]$ & $16.887 \pm 6.671$ & $54.505 \pm 14.033$ & 0.000 \\
\hline LA peak systolic strain [\%] & $15.565 \pm 5.796$ & $36.159 \pm 10.499$ & 0.000 \\
\hline
\end{tabular}

Data are shown as number (percentage) or mean \pm standard deviation. ACEI/ARB - angiotensin converting enzyme inhibitors/angiotensin II receptor blockers; $\mathrm{AF}$ - atrial fibrillation; $\mathrm{BMI}$ - body mass index; $\mathrm{BUN}$ - blood urea nitrogen; $\mathrm{E} / \mathrm{e}^{\prime}$ ratio - the ratio of the early transmitral flow velocity and the early mitral annular velocity; LA — left atrium; LAAeV — LAA emptying flow velocity; LAAT — left atrial appendage thrombus; LAD - left atrial dimension; LAVmax - maximal left atrial volume; LVDd — left ventricular end-diastolic dimension; LVEF - left ventricular ejection fraction; SEC — spontaneous echocardiographic contrast; TIA - transient ischemic attack

The percentage of ACEIs/ARBs users and antiplatelet drug users were higher in patients without LAAT $(48.6 \%)$ than those with LAAT $(32.7 \%)(\mathrm{p}<$ $<0.05)$. In LAAT patients, $16.4 \%$ patients had used ACEIs and $16.4 \%$ had used ARBs. There were no significant differences in LVDd and LVEF between the two groups. Lower LA peak systolic strains and LAAeV were observed in patients with LAAT. Tendency for higher E/e' ratio, LAD and LAVmax was shown in patients with LAAT (Table 2).

Subgroup analysis demonstrated no significant difference in incidence of LAAT between 
Table 3. Clinical and echocardiographic parameters between patients with ACEls and ARBs.

\begin{tabular}{|c|c|c|c|}
\hline Variables & ACEls user $(n=36)$ & ARBs user $(n=52)$ & $\mathbf{P}$ \\
\hline Age [years] & $62.416 \pm 7.299$ & $63.019 \pm 8.806$ & 0.736 \\
\hline Age $\geq 65$ years & $13(36.1 \%)$ & $25(48.1 \%)$ & 0.265 \\
\hline Male gender & $19(52.8 \%)$ & $29(55.8 \%)$ & 0.782 \\
\hline BMI $\left[\mathrm{kg} / \mathrm{m}^{2}\right]$ & $26.105 \pm 3.645$ & $26.426 \pm 4.095$ & 0.287 \\
\hline AF type: & $36(40.9 \%)$ & $52(59.1 \%)$ & 0.341 \\
\hline Paroxysmal AF & $25(69.4 \%)$ & $43(82.7 \%)$ & 0.145 \\
\hline Persistent AF & $10(27.8 \%)$ & $8(15.4 \%)$ & 0.156 \\
\hline Long standing persistent AF & $1(2.8 \%)$ & $1(1.9 \%)$ & 1.000 \\
\hline Medication time [months] & $15.916 \pm 13.296$ & $14.067 \pm 10.558$ & 0.470 \\
\hline Old myocardial infarction & $1(2.8 \%)$ & $4(7.7 \%)$ & 0.645 \\
\hline Vascular disease & $2(5.6 \%)$ & $2(3.8 \%)$ & 1.000 \\
\hline Coronary heart disease & $30(83.3 \%)$ & $36(69.2 \%)$ & 0.133 \\
\hline Hyperlipidemia & $21(58.3 \%)$ & $38(73.1 \%)$ & 0.148 \\
\hline Hypertension & $31(86.1 \%)$ & $46(88.5 \%)$ & 0.754 \\
\hline Diabetes mellitus & $6(16.7 \%)$ & $17(32.7 \%)$ & 0.093 \\
\hline Congestive heart failure & $3(8.3 \%)$ & $3(5.8 \%)$ & 0.685 \\
\hline Prior stroke or TIA & $4(11.1 \%)$ & $6(11.5 \%)$ & 1.000 \\
\hline $\mathrm{CHA}_{2} \mathrm{DS}_{2}$-VASc score & $2.277 \pm 1.365$ & $2.596 \pm 1.375$ & 0.287 \\
\hline Smoking history & $13(36.1 \%)$ & $22(42.3 \%)$ & 0.559 \\
\hline Drinking history & $8(22.2 \%)$ & $13(25 \%)$ & 0.764 \\
\hline Antiplatelet drugs & $21(58.3 \%)$ & $29(55.8 \%)$ & 0.811 \\
\hline Statins & $16(44.4 \%)$ & $27(51.9 \%)$ & 0.490 \\
\hline $\mathrm{BUN}[\mathrm{mmol} / \mathrm{L}]$ & $6.122 \pm 1.578$ & $5.586 \pm 1.510$ & 0.112 \\
\hline Serum creatinine $[\mu \mathrm{mol} / \mathrm{L}]$ & $75.847 \pm 20.301$ & $80.219 \pm 29.107$ & 0.438 \\
\hline LAD $[\mathrm{mm}]$ & $39.561 \pm 3.906$ & $39.299 \pm 3.902$ & 0.757 \\
\hline LAVmax $[\mathrm{mL}]$ & $50.538 \pm 15.848$ & $50.382 \pm 13.837$ & 0.961 \\
\hline LVDd [mm] & $49.846 \pm 6.033$ & $49.016 \pm+6.626$ & 0.551 \\
\hline LVEF [\%] & $58.649 \pm 6.646$ & $56.799 \pm 6.242$ & 0.187 \\
\hline E/e' ratio & $12.436 \pm 3.968$ & $11.982 \pm 4.787$ & 0.641 \\
\hline LAAeV $[\mathrm{cm} / \mathrm{s}]$ & $46.405 \pm 20.706$ & $48.115 \pm 19.151$ & 0.691 \\
\hline LA peak systolic strain [\%] & $32.822 \pm 13.730$ & $34.403 \pm 12.826$ & 0.582 \\
\hline SEC & $15(41.7 \%)$ & $16(30.8 \%)$ & 0.293 \\
\hline LAAT & $9(25 \%)$ & $9(17.3 \%)$ & 0.379 \\
\hline
\end{tabular}

Data are shown as number (percentage) or mean \pm standard deviation. ACEI/ARB - angiotensin converting enzyme inhibitors/angiotensin II receptor blockers; $\mathrm{AF}$ - atrial fibrillation; $\mathrm{BMI}$ — body mass index; $\mathrm{BUN}$ - blood urea nitrogen; E/e' ratio - the ratio of the early transmitral flow velocity and the early mitral annular velocity; LA — left atrium; LAAeV — LAA emptying flow velocity; LAAT — left atrial appendage thrombus; LAD - left atrial dimension; LAVmax - maximal left atrial volume; LVDd - left ventricular end-diastolic dimension; LVEF - left ventricular ejection fraction; SEC — spontaneous echocardiographic contrast; TIA — transient ischemic attack

the ACEIs users (25\%) and ARBs users group $(17.3 \%)(\mathrm{p}=0.379)$ (Table 3, Fig. 2). Moreover, no statistically significant differences in other clinical characteristics and echocardiographic parameters were observed between the ACEIs and ARBs groups (Table 3). Patients with ARBs demonstrated significantly less incidence of LAAT compared to the nonuser group $(p=0.034)$ (Fig. $2 A)$. Interestingly, LA peak systolic strain was significantly increased both in the ARBs group $(p=0.003)$ and the ACEIs group compared to the non-user group $(\mathrm{p}=0.048)$ (Fig. 2B).

Logistic regression analysis was performed to identify independent clinical predictors of LAAT (Table 4). Univariate analysis demonstrated that age, BMI, AF type, hypertension, diabetes mellitus, prior stroke or TIA, drinking history, LAVmax, usage of ACEIs/ARBs and antiplatelet drugs 


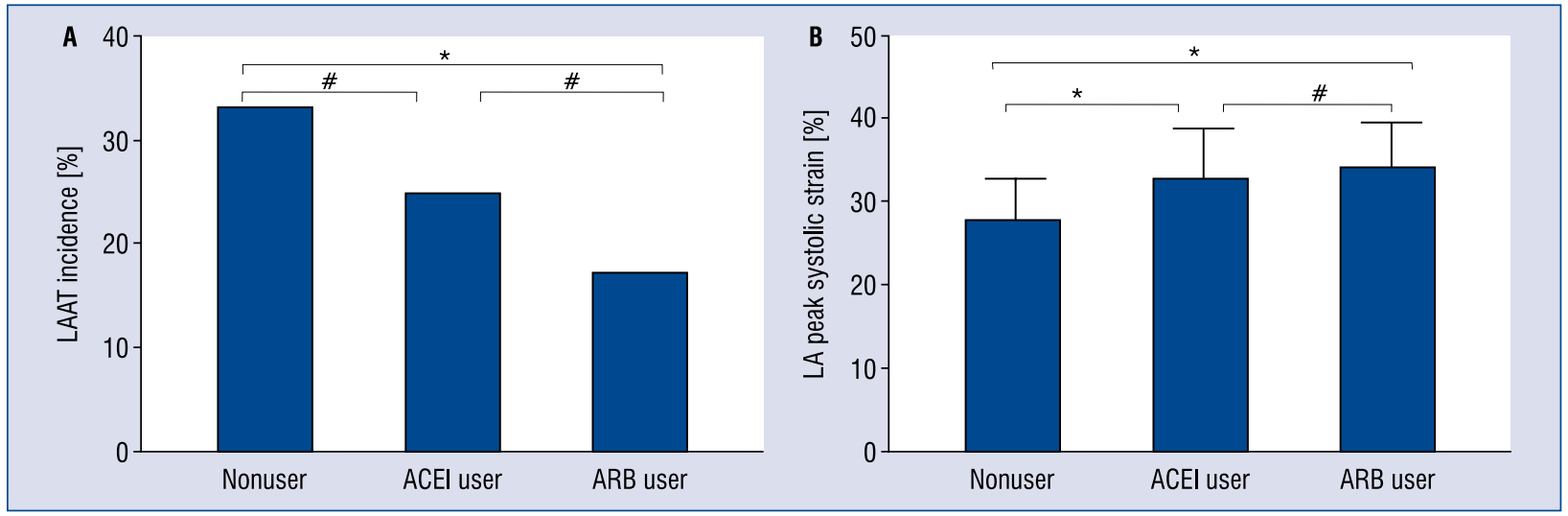

Figure 2. Left atrial appendage thrombus (LAAT) incidence and left atrium (LA) peak systolic strain in patients with angiotensin converting enzyme inhibitors (ACEls) angiotensin II receptor blockers (ARBs) and without ACEls/ARBs; A. LAAT incidence in patients with ACEls, ARBs and nonuse; B. LA peak systolic strain in patients with ACEls, ARBs and nonuser; ${ }^{*} p<0.05 ; \# p>0.05$.

Table 4. Multivariate logistic regression analyses for left atrial appendage thrombus.

\begin{tabular}{lccc}
\hline Variables & Odds ratio & $95 \% \mathrm{Cl}$ & $\mathbf{P}$ \\
\hline Age $\geq 65$ years & 2.166 & $0.906-5.178$ & 0.082 \\
LAVmax $\geq 50 \mathrm{~mL}$ & 3.491 & $1.343-9.074$ & 0.010 \\
Body mass index & 1.012 & $0.893-1.148$ & 0.848 \\
AF type & & & 0.093 \\
Hypertension & 4.377 & $1.601-11.969$ & 0.004 \\
Diabetes mellitus & 1.917 & $0.636-5.775$ & 0.248 \\
Prior stroke or TIA & 17.342 & $2.937-102.412$ & 0.002 \\
Drinking history & 2.011 & $0.686-5.892$ & 0.203 \\
ACEl/ARB & 0.222 & $0.084-0.585$ & 0.002 \\
Antiplatelet drugs & 0.370 & $0.151-0.905$ & 0.029 \\
\hline
\end{tabular}

$\mathrm{ACEI} / \mathrm{ARB}$ - angiotensin converting enzyme inhibitors/angiotensin II receptor blockers; $\mathrm{AF}$ — atrial fibrillation; $\mathrm{Cl}$ - confidence interval; LAVmax - maximal left atrial volume; TIA — transient ischemic attack

were significantly associated with LAAT. However, only the categories of AF type, age $\geq 65$ years, hypertension, prior stroke or TIA, LAVmax $\geq 50 \mathrm{~mL}$, usage of ACEIs/ARBs and antiplatelet drugs were associated with LAAT following multivariate adjustments (Table 4). After controlling for the factors related to LAAT, the use of RAS inhibitors remained significantly associated with a lower risk of LAAT incidence $(\mathrm{OR}=0.222 ; 95 \%$ CI $0.084-0.585$, $\mathrm{p}=0.002)($ Table 4$)$.

\section{Discussion}

\section{Major findings}

The major finding of the present study is that the use of RAS inhibitors was associated with a lower incidence of LAAT in patients with AF. According to available literature, this is the first clinical study that has assessed the antithrombotic property of RAS inhibitors with respect to LAAT prevention using echocardiography.

\section{Roles of RAS in atrial remodeling and LAA thrombus}

Renin-angiotensin system activation is known to play a critical role in structural and electrophysiological remodeling in the atrial myocardium, which can increase the susceptibility to arrhythmia and the development of AF [16]. Besides, adverse hemodynamic effects, activation of multiple cell signaling cascades facilitates increased intracellular calcium, hypertrophy, apoptosis, cytokine 
release, inflammation, oxidative stress and expression of growth-related factors that also stimulate fibrosis, possible modulation of ion channel and gap-junction dynamics. Electrical contractile and structural remodeling are dominant factors for $\mathrm{AF}$ genesis. Fibrosis is part of the structural remodeling process [17], which can negatively impact on the mechanical function of the atria, in turn predisposing to thrombus formation in the LAA $[4,5]$. These findings seem physiologically reasonable, as atrial emptying is attenuated with impaired LA function and elevated LA fibrosis, causing atrial blood stasis and thrombus formation [18].

\section{Left atrial peak systolic strain and the risk of LAA thrombus}

The presence of SEC or reduced LAA emptying velocity (LAAeV), as measured using TEE, has been shown to be helpful in detecting LAA dysfunction [3] and provides useful markers for stratification of thromboembolic risk in patients with $\mathrm{AF}$ [4]. 2D speckle-tracking strain imaging is a novel method for quantitative real-time assessment of regional myocardial deformation which uses tracking of acoustic speckles or kernels instead of Doppler myocardial velocities [19]. Recently, this technique has been recommended for the quantification of LA myocardial deformation and indicated to evaluate the atrial function accurately during the different phases of the cardiac cycle [20]. LA mechanical function can be broadly divided into reservoir, conduit and pump function. The burden of LA fibrosis, analyzed by magnetic resonance imaging, displays an inverse correlation with LA strain evaluated by $2 \mathrm{D}$ speckle tracking [7]. LA reverse remodeling could be predicted independently by LA systolic strain [21]. These results indicated that LA peak systolic strain is correlated with mechanical and structural remodeling of the LA and is helpful to assess LA reservoir function [22]. One study showed that LA peak systolic strain was dramatically correlated with LAAeV in patients with AF [23]. LA peak systolic strain was decreased with LA enlargement and increasing age. Decreasing LA peak systolic strain (normal value $42.2 \pm 6.1 \%$ ) was considered as a reliable marker of LAA dysfunction and thrombus risk in patients with AF $[23,24]$.

\section{Maximal left atrial volume and the risk of LAA thrombus}

Enlargement of LA is associated with aging, hypertension, and LV diastolic dysfunction, and is an independent factor of AF [25]. Conversely, AF itself can enhance LA remodeling and higher AF burden can also lead to LA enlargement [25]. An enlarged LA could be a predictive factor for the occurrence of stroke [26]. A previous study has shown that LA volume was correlated with LAA maximal area, which was an independent predictor for LAA thrombus formation [27]. In the present study, the maximum LA volume (LAVmax) was found to be an independent risk factor for LAAT even after adjusting for other factors such as aging and hypertension. It suggested that dilation of left cardiac chambers offered a suitable terrain for thrombus formation.

\section{Roles of RAS inhibitors in atrial remodeling and thrombus formation}

Among the components of renin-angiotensin-aldosterone system (RAAS), ACE and angiotensin II are known to contribute to atrial fibrotic remodeling during AF. RAAS inhibitors containing ACEIs or ARBs are involved in upstream therapy. They can reduce atrial stretch, fibrosis and reverse remodeling process via RAAS inhibition and may lower the development of AF [28]. The present study demonstrated decreased LA peak systolic strains in LAAT patients. Patients who used ACEIs/ARBs had significantly greater LA peak systolic strains and lesser incidence of LAAT compared to those who didn't use ACEIs/ARBs. Multivariate logistic regression analysis showed that RAS inhibitors were independently associated with lower risk of LAAT.

\section{Differences between the effects of ARBs and ACEIs on LAA thrombus}

Subgroup analysis demonstrated no significant differences in clinical characteristics, echocardiographic parameters and incidence of LAAT between patients on ACEIs and those on ARBs. LAAT incidence was significantly reduced in ARBs group, and tended to be reduced in ACEIs group when compared with non-user group. However, it was not significantly different between ARBs vs. ACEIs groups. Interestingly, LA peak systolic strains in patients with ACEIs or ARBs were significantly increased compared to the non-user group. Several studies have reported antiplatelet, anticoagulant and pro-fibrinolytic effects of ARBs [29-31]. Moreover, angiotensin II AT-1-type receptor antagonists can reduce TxA2-dependent activation independent of angiotensin II involvement. Indeed, inhibitory effects on platelet activation by some ARBs such as losartan have been reported to be as high as those of acetylsalicylic acid (ASA) [32]. 
ARBs can decrease the expression of the arterial adhesion molecule, vascular cell adhesion protein-1 (VCAM-1), and endothelial fibrosis, both of which are implicated in the thrombogenic process [33, $34]$. In the present study, the use of ARBs might indeed have greater direct antiplatelet, anticoagulant and other reverse-remodeling actions compared to ACEIs, and thus contributed to a lower the incidence of LAAT.

Results herein indicate that ACEIs and ARBs can reduce LAAT risk. In the present study, patients who have been treated with anticoagulation therapy were excluded. However, some other drugs have been considered to have an effect on LAAT. For example, the SPAF-1 trial shows benefit for ASA alone in preventing stroke among patients with AF. For primary prevention, ASA use was associated with a $19 \%$ reduction in stroke incidence with an absolute risk reduction of $0.8 \%$ per year. For secondary prevention among those with TIA or strokes, ASA use was associated with an absolute risk reduction of $2.5 \%$ per year [35, 36]. Moreover, several systematic reviews have demonstrated the beneficial effects of statin therapy in preventing AF [37, $38]$. In the present study, antiplatelet drugs were an independent predictor of LAAT $(\mathrm{OR}=0.370$; 95\% CI 0.151-0.905; $\mathrm{p}=0.029)$. However, there was no interaction between the usage of ACEIs/ /ARBs and antiplatelet agents. It is notable that even after adjusting for dosage of antiplatelet drug, the relationship between ACEIs/ARBs users and the risk of LAAT was not significantly altered. However, statin use was not significantly correlated with the incidence of LAAT.

\section{Limitations of the study}

There are several intrinsic limitations of this study which should be noted. Firstly, it is a hospital-based retrospective study. Secondly, the sample size was small with a limited number of events. Thirdly, ascertainment bias was a possibility. Although medication reconciliation forms were used to assess the duration of ACEIs/ARBs usage, but this may not reflect medication adherence. Fourthly, there was an inability to assess the dosage-related effects in this study, partly due to frequent dosage alterations during the course of the study. Finally, blood coagulation-related parameters were not recorded.

\section{Conclusions}

In summary, this study showed that the use of RAS inhibitors might be associated with reverse
LA remodeling and a reduction in the risk of LAAT. Larger, prospective studies are needed to ascertain the benefit of RAS inhibition in reducing the incidence of LAAT.

\section{Acknowledgements and funding}

This work was supported by science and technology foundation of Tianjin sanitary bureau (2015KZ105) and Tianjin Natural Science Foundation (16JCYBJC25000) to H.F.

\section{Conflict of interest: None declared}

\section{References}

1. Fuster V, Rydén LE, Cannom DS, et al. ACC/AHA/ESC 2006 guidelines for the management of patients with atrial fibrillation - executive summary: a report of the American College of Cardiology/American Heart Association Task Force on Practice Guidelines and the European Society of Cardiology Committee for Practice Guidelines (Writing Committee to Revise the 2001 Guidelines for the Management of Patients With Atrial Fibrillation). J Am Coll Cardiol. 2006; 48(4): 854-906, doi: 10.1016/j. jacc.2006.07.009, indexed in Pubmed: 16904574.

2. Takada T, Yasaka M, Nagatsuka K, et al. Blood flow in the left atrial appendage and embolic stroke in nonvalvular atrial fibrillation. Eur Neurol. 2001; 46(3): 148-152, doi: 50788, indexed in Pubmed: 11598333.

3. Zabalgoitia M, Halperin JL, Pearce LA, et al. Transesophageal echocardiographic correlates of clinical risk of thromboembolism in nonvalvular atrial fibrillation. Stroke Prevention in Atrial Fibrillation III Investigators. J Am Coll Cardiol. 1998; 31(7): 1622-1626, indexed in Pubmed: 9626843.

4. Kamp O, Verhorst PM, Welling RC, et al. Importance of left atrial appendage flow as a predictor of thromboembolic events in patients with atrial fibrillation. Eur Heart J. 1999; 20(13): 979-985, doi: 10.1053/euhj.1998.1453, indexed in Pubmed: 10361051.

5. Sparks PB, Mond HG, Vohra JK, et al. Mechanical remodeling of the left atrium after loss of atrioventricular synchrony. A longterm study in humans. Circulation. 1999; 100(16): 1714-1721, indexed in Pubmed: 10525491.

6. Healey JS, Baranchuk A, Crystal E, et al. Prevention of atrial fibrillation with angiotensin-converting enzyme inhibitors and angiotensin receptor blockers: a meta-analysis. J Am Coll Cardiol. 2005; 45(11): 1832-1839, doi: 10.1016/j.jacc.2004.11.070, indexed in Pubmed: 15936615.

7. Remková A, Remko M. The role of renin-angiotensin system in prothrombotic state in essential hypertension. Physiol Res. 2010; 59(1): 13-23, indexed in Pubmed: 19249905.

8. Brown NJ, Vaughan DE. Prothrombotic effects of angiotensin. Adv Intern Med. 2000; 45: 419-429, indexed in Pubmed: 10635057.

9. Kuppahally SS, Akoum N, Burgon NS, et al. Left atrial strain and strain rate in patients with paroxysmal and persistent atrial fibrillation: relationship to left atrial structural remodeling detected by delayed-enhancement MRI. Circ Cardiovasc Imaging. 2010; 3(3): 231-239, doi: 10.1161/CIRCIMAGING.109.865683, indexed in Pubmed: 20133512.

10. Lang RM, Bierig M, Devereux RB, et al. Chamber Quantification Writing Group, American Society of Echocardiography's Guidelines and Standards Committee, European Association of Echocardiography. Recommendations for chamber quantification: 
a report from the American Society of Echocardiography's Guidelines and Standards Committee and the Chamber Quantification Writing Group, developed in conjunction with the European Association of Echocardiography, a branch of the European Society of Cardiology. J Am Soc Echocardiogr. 2005; 18(12): 1440-1463, doi: 10.1016/j.echo.2005.10.005, indexed in Pubmed: 16376782.

11. Aschenberg W, Schlüter M, Kremer P, et al. Transesophageal two-dimensional echocardiography for the detection of left atrial appendage thrombus. J Am Coll Cardiol. 1986; 7(1): 163-166, indexed in Pubmed: 3941205.

12. Fatkin D, Herbert E, Feneley MP. Hematologic correlates of spontaneous echo contrast in patients with atrial fibrillation and implications for thromboembolic risk. Am J Cardiol. 1994; 73(9): 672-676, indexed in Pubmed: 8166064.

13. Fatkin D, Kelly RP, Feneley MP. Relations between left atrial appendage blood flow velocity, spontaneous echocardiographic contrast and thromboembolic risk in vivo. J Am Coll Cardiol. 1994; 23(4): 961-969, indexed in Pubmed: 8106703.

14. Troughton RW, Asher CR, Klein AL. The role of echocardiography in atrial fibrillation and cardioversion. Heart. 2003; 89(12): 1447-1454, indexed in Pubmed: 14617563.

15. Puwanant S, Varr BC, Shrestha K, et al. Role of the CHADS2 score in the evaluation of thromboembolic risk in patients with atrial fibrillation undergoing transesophageal echocardiography before pulmonary vein isolation. J Am Coll Cardiol. 2009; 54(22): 2032-2039, doi: 10.1016/j.jacc.2009.07.037, indexed in Pubmed: 19926009.

16. Schotten U, Verheule S, Kirchhof P, et al. Pathophysiological mechanisms of atrial fibrillation: a translational appraisal. Physiol Rev. 2011; 91(1): 265-325, doi: 10.1152/physrev.00031.2009, indexed in Pubmed: 21248168.

17. Burstein B, Nattel S. Atrial fibrosis: mechanisms and clinical relevance in atrial fibrillation. J Am Coll Cardiol. 2008; 51(8): 802-809, doi: 10.1016/j.jacc.2007.09.064, indexed in Pubmed: 18294563.

18. Doukky R, Garcia-Sayan E, Gage H, et al. The value of diastolic function parameters in the prediction of left atrial appendage thrombus in patients with nonvalvular atrial fibrillation. Cardiovasc Ultrasound. 2014; 12: 10, doi: 10.1186/1476-7120-12-10, indexed in Pubmed: 24568305.

19. Leitman M, Lysyansky P, Sidenko S, et al. Two-dimensional strain-a novel software for real-time quantitative echocardiographic assessment of myocardial function. J Am Soc Echocardiogr. 2004; 17(10): 1021-1029, doi: 10.1016/j.echo.2004.06.019, indexed in Pubmed: 15452466.

20. Cianciulli TF, Saccheri MC, Lax JA, et al. Two-dimensional speckle tracking echocardiography for the assessment of atrial function. World J Cardiol. 2010; 2(7): 163-170, doi: 10.4330/wjc. v2.i7.163, indexed in Pubmed: 21160748.

21. Machino-Ohtsuka T, Seo Y, Ishizu T, et al. Significant improvement of left atrial and left atrial appendage function after catheter ablation for persistent atrial fibrillation. Circ J. 2013; 77(7): 1695-1704, indexed in Pubmed: 23535197.

22. Kokubu N, Yuda S, Tsuchihashi K, et al. Noninvasive assessment of left atrial function by strain rate imaging in patients with hypertension: a possible beneficial effect of renin-angiotensin system inhibition on left atrial function. Hypertens Res. 2007; 30(1): 13-21, doi: 10.1291/hypres.30.13, indexed in Pubmed: 17460367.

23. Sasaki S, Watanabe T, Tamura H, et al. Left atrial strain as evaluated by two-dimensional speckle tracking predicts left atrial appendage dysfunction in patients with acute ischemic stroke. BBA Clin. 2014; 2: 40-47, doi: 10.1016/j.bbacli.2014.09.004, indexed in Pubmed: 26672873.
24. Cameli M, Caputo M, Mondillo S, et al. Feasibility and reference values of left atrial longitudinal strain imaging by two-dimensional speckle tracking. Cardiovasc Ultrasound. 2009; 7: 6, doi: 10.1186/1476-7120-7-6, indexed in Pubmed: 19200402.

25. Thamilarasan M, Klein AL. Factors relating to left atrial enlargement in atrial fibrillation: „chicken or the egg” hypothesis. Am Heart J. 1999; 137(3): 381-383, indexed in Pubmed: 10047615.

26. Barnes ME, Miyasaka Y, Seward JB, et al. Left atrial volume in the prediction of first ischemic stroke in an elderly cohort without atrial fibrillation. Mayo Clin Proc. 2004; 79(8): 1008-1014, doi: 10.4065/79.8.1008, indexed in Pubmed: 15301328.

27. Bakalli A, Georgievska-Ismail L, Koçinaj D, et al. Prevalence of left chamber cardiac thrombi in patients with dilated left ventricle at sinus rhythm: the role of transesophageal echocardiography. J Clin Ultrasound. 2013; 41(1): 38-45, doi: 10.1002/ /jcu.21953, indexed in Pubmed: 22729833.

28. Nakashima H, Kumagai K. Reverse-remodeling effects of angiotensin II type 1 receptor blocker in a canine atrial fibrillation model. Circ J. 2007; 71(12): 1977-1982, indexed in Pubmed: 18037757.

29. Sakamoto T, Kudoh T, Sakamoto K, et al. Antithrombotic effects of losartan in patients with hypertension complicated by atrial fibrillation: 4A (Angiotensin II Antagonist of platelet Aggregation in patients with Atrial fibrillation), a pilot study. Hypertens Res. 2014; 37(6): 513-518, doi: 10.1038/hr.2014.22, indexed in Pubmed: 24572913.

30. Guerra-Cuesta JI, Montón M, Rodríguez-Feo JA, et al. Effect of losartan on human platelet activation. J Hypertens. 1999; 17(3): 447-452, indexed in Pubmed: 10100084.

31. Soejima H, Ogawa H, Suefuji H, et al. Comparison of effects of losartan versus enalapril on fibrinolysis and coagulation in patients with acute myocardial infarction. Am J Cardiol. 2001; 87(12): 1408-1411, indexed in Pubmed: 11397366.

32. Montón M, Jiménez A, Núñez A, et al. Comparative effects of angiotensin II AT-1-type receptor antagonists in vitro on human platelet activation. J Cardiovasc Pharmacol. 2000; 35(6): 906-913, indexed in Pubmed: 10836725.

33. Choi JI, Jung JS, Kim MK, et al. Effects of angiotensin-II receptor blocker on inhibition of thrombogenicity in a canine atrial fibrillation model. Korean Circ J. 2016; 46(3): 335-342, doi: 10.4070/ /kcj.2016.46.3.335, indexed in Pubmed: 27275170.

34. Hiczkiewicz J, Koźluk E, Łojewska K, et al. Takotsubo syndrome after pericardial tamponade following cryoballoon ablation of pulmonary veins for paroxysmal atrial fibrillation and complicated by right coronary artery thrombosis. Cardiol J. 2017; 24(2): 216, doi: 10.5603/CJ.2017.0040, indexed in Pubmed: 28421588.

35. Zimetbaum PJ, Thosani A, Yu HT, et al. Are atrial fibrillation patients receiving warfarin in accordance with stroke risk? Am J Med. 2010; 123(5): 446-453, doi: 10.1016/j.amjmed.2009.11.015, indexed in Pubmed: 20399322.

36. Amraotkar AR, Ghafghazi S, Trainor PJ, et al. Presence of multiple coronary angiographic characteristics for the diagnosis of acute coronary thrombus. Cardiol J. 2017; 24(1): 25-34, doi: 10.5603/CJ.a2017.0004, indexed in Pubmed: 28150291.

37. Liu T, Li L, Korantzopoulos P, et al. Statin use and development of atrial fibrillation: a systematic review and meta-analysis of randomized clinical trials and observational studies. Int J Cardiol. 2008; 126(2): 160-170, doi: 10.1016/j.jijcard.2007.07.137, indexed in Pubmed: 18031847.

38. Nowak R, Fijalkowska M, Gilis-Malinowska N, et al. Left ventricular function after takotsubo is not fully recovered in long-term follow-up: A speckle tracking echocardiography study. Cardiol J. 2017; 24(1): 57-64, doi: 10.5603/CJ.a2017.0001, indexed in Pubmed: 28070881. 